\title{
Evaluation of compact water treatment units using reverse osmosis (RO) technology in Marioutia region, Giza -Egypt.
}

Magdy M.Fakhr, Safinaz A. Farfour, Abdel-Hameed M. Othman, Ibrahim E. Mousa*

Environmental biotechnology department, Genetic engineering and biotechnology research institute, University of Sadat city, Egypt.

*Corresponding author: ibrahim.mousa@gebri.usc.edu.eg

\begin{abstract}
A common treatment strategy for iron and manganese control in drinking water includes oxidation of dissolved iron and manganese followed by separation of oxidized particles from water by reverse osmosis technology. The samples are analyzed for physico-chemical parameters. Further the correlation studies among the heavy metals of water were estimated. The results were compared with drinking water standards of World Health Organization. The analytical data of $\mathrm{pH}$ and total dissolved solids (TDS) showed that all samples of ground water are suitable as drinking water according to the World Health Organization standards (WHO 2011). Nevertheless, Fe and Mn were noted higher than the WHO allowable limits, what would be ascribed to erosion and leaching of soil and rocks. The total removal\% of TDS resulted from three compact RO units were $42.0 \%, 46.8 \%$ and $63.1 \%$, respectively. In addition, our results showed that the change in ground water quality did not an influence on the quality and safety of produced water, and our study identified that Fe and Mn removal filters could play an important role in the pretreatment and quality development of final products.

Keywords: groundwater, iron, manganese, chlorination, brim filter, Reverse osmosis.
\end{abstract}

\section{INTRODUCTION}

In suburban area, the drinking water availability through groundwater resources has become more critical issues today. The ground water is susceptible to pollution due to excessive usage of fertilizers, pesticides, increased anthropogenic activities and fast growth of industries. Moreover, ground water resources have different qualities, get pollution and unfit for direct usages (Stavridis et al., 2017). The problem with most of these studies worldwide, there are several states are dependent on groundwater for drinking and other purposes (Alemayehu, 2004).

Supply of safe drinking water is crucial to human life, and safe drinking water should not impose a significant risk to humans (WHO, 2011). Although few heavy metals are essential for human health, an excess amount of these metals can have negative effects (USEPA, 2015). The heavy metals are released into the environment through natural process and anthropogenic activities. The industrial processes generate wastes, which are mostly discharged into the environment.

The use of groundwater has increased significantly in the last decades due to its widespread occurrence and overall good quality. Groundwater is the main source of drinking water in suburban area. Hence the present study has been undertaken to determine the physico-chemical characteristics of groundwater in some selected locations of Giza governorate. Various water samples were taken at three different locations (Mishra et al., 
2002). In this regard, the United States Environmental Protection Agency (EPA, 2002) and Guidelines for Canadian Drinking Water Quality have recommended an aesthetic objective limit of 0.3 and $0.05 \mathrm{mg} / \mathrm{L}$ for the concentrations of iron and manganese in drinking water, respectively. However, Iron and manganese concentrations as low as 0.05 and $0.02 \mathrm{mg} / \mathrm{L}$ (WHO, 2004), respectively, may still cause aesthetic problems.

Traditional processes to remove particulate and colloidal matter from water are coagulation, flocculation, sedimentation and granular media filtration, which have drawbacks of operating in successive Steps heterogeneous reactions that require significant contact time and, therefore, process footprint. Furthermore, oxidized manganese is not always effectively removed by such treatment technologies due to its propensity to form small colloids. Alternatively, compact membrane processes, such as microfiltration (MF) and ultra filtration (UF), are increasingly used in water treatment facilities for filtration of dilute suspensions containing fine particles and colloids based on size exclusion (Crittenden et al., 2012).

But also highlight that even relevant treatment technologies may have considerable hurdles to handle practical treatment applications at the field-scale (Vecitiset al., 2009; Du et al., 2014; Merino et al., 2016; Kucharzyket al., 2017; Ross et al., 2018) and the inapplicability of conventional treatment technologies (Appleman et al., 2014; Higgins and Dickenson, 2016) but also highlight that even relevant treatment technologies may have considerable hurdles to handle practical treatment applications at the field-scale (Vecitis et al., 2009; Du et al., 2014; Merino et al.,
2016; Kucharzyk et al., 2017; Ross et al., 2018) and the inapplicability of conventional treatment technologies (Appleman et al., 2014; Higgins and Dickenson, 2016).

Management of membrane fouling is an important limitation of this technology. As opposed to ground water systems where organic fouling is not dominant, management of inorganic fouling caused by iron/manganese is of importance for many UF/MF groundwater systems. Several factors impact membrane fouling including membrane types and material properties, operating conditions, process configuration, cleaning strategies and feed solution characteristics (Crittenden et al., 2012, Lee and Kim, 2014).

Ground water is the basic resource of drinking water in suburban area. The ground water is potable when compared to surface water. However, the ground water is susceptible to pollution due to excessive usage of fertilizers, pesticides, increased anthropogenic activities and fast growth of industries. The present study was taken under investigation to analyze the impact of Compact treatment units depending on reverse Osmosis technology on groundwater quality of certain open wells. Well water samples in selected locations in Giza, Egypt. Thus, in this research study an attempt has been made to assess the physic-chemical parameters of groundwater for temperature $(T), p H$, electrical conductivity (EC) total dissolved solids (TDS), magnesium $(\mathrm{Mg})$, Iron (Fe) and other heavy metals. The analyzed data were then compared with the standard values of $\mathrm{WHO}$. The correlation coefficients were calculated to assess the 


\section{MATERIALS AND METHODS}

The present study has been undertaken to determine the physico-chemical and characteristics of groundwater in selected three locations of Giza governorate, Egypt. Various water samples were taken at three different locations. The drinking water treatment compact units were selected for an integrated comparative studies to evaluate their overall performance to provide potable water with acceptable quality based on WHO (2008) the Egyptian standards and guidelines (2006). Details of various methods adopted for physical, chemical, and heavy metals analyses are also included. Three different units in Marioutia, Giza governorate were selected for integrated comparative study. The evaluation tools of the comparative studies include physical, chemical and metal parameters pertaining potential significance to water quality characterization.

Total dissolved salts (TDS)

Total dissolved salts were measured directly using Loviebond multi parameters kit (model p 15, Germany) and the results were expressedas ppm.

\section{Hydrogen ion concentration ( $\mathrm{pH})$}

The $\mathrm{pH}$ values of water samples were directly measured using a Loviebond multi parameters kit (model p 15, Germany).

\section{Metal determination by ICP-MS}

A total of $500 \mathrm{ml}$ of each sample or any available volume were digested with $3 \mathrm{ml}$ of Aquilegia (a mixture of $69 \% \mathrm{HNO}_{3}, \mathrm{concHCl}$ $(3: 1 v / v))$ in a heating digester (DK 20, Blender Scientifica, Germany).The extracts were filtered through disposable $0.2 \mu \mathrm{m}$ PTFE syringe filters (DISMIC-25HP, Advantec,
Tokyo, Japan). The metal concentrations in these extracts were determined by means of inductively coupled plasma-mass spectroscopy (ICP-MS) (iCAP, Thermo, Germany). Certified reference materials (Merck, Germany) were included in the analyses. The recovery of metals was within the certified limits. Qtegra software was used for average and relative standard deviation calculation (APHA, 2005; Lambers et al., 2008).

\section{Removal Efficiency}

It is important to be able to evaluate the rate at which contaminants are removed in order to design the full scale application of the technology (Rajic et al., 2016). TPH removal efficiency was calculated by the following equation:

Removal\% $\% \frac{C 0-C t}{C 0} * 100(1)$
where $\mathrm{Co}$ is the initial $\mathrm{TPH}$
concentration $(\mathrm{mg} / \mathrm{L})$ and $\mathrm{Ct}$ is $\mathrm{TPH}$
concentration at a defined time during
treatment $(\mathrm{mg} / \mathrm{L})$.

\section{Data analysis}

Graphs and chats were constructed using MS office Excel version 2013 and Statistical Package for Social Sciences (SPSS) version 17 software was used in the analysis. $95 \%$ level of significance was used as the critical point $(P=<0.05)$. The collected data on the physic-chemical parameters, density of indicator were appropriately subjected to statistical analysis to find their corresponding mean variations. The means were compared using one way Analysis of variance (ANOVA) and Least Significance difference (LSD) used in separating the mean sunder the post hoc test. 


\section{RESULTS AND DISCUSSION}

\section{General indicators and treatment efficiencies}

Table (1) shows the results of ground water analysis feed three different plants. The water have low concentration of dissolved salts with range from 256 to 332 ppm with slight alkaline but included high concentration of iron and manganese above the limit of $\mathrm{WHO}$ and Egyptian guidelines. The design of the different plants to produce treated water were in the range $15-20 \mathrm{~m}^{3} / \mathrm{d}$ and the reject water ranged from was used for washing screens, blankets, cloth and winch machines including ash quenching within the industry.

Table (1) General indicators analysis of ground waters of three different copmact units comparing to WHO standards.

\begin{tabular}{|c|c|c|c|c|c|}
\hline & $\mathrm{pH}$ & $\begin{array}{c}\mathrm{EC} \\
(\mu \mathrm{S} / \mathrm{cm})\end{array}$ & $\begin{array}{c}\text { TDS } \\
(\mathrm{ppm})\end{array}$ & $\begin{array}{c}\mathrm{Fe} \\
(\mathrm{ppm})\end{array}$ & $\begin{array}{c}\mathrm{Mn} \\
(\mathrm{ppm})\end{array}$ \\
\hline Plant 1 & $7.84 \pm 0.13$ & $456 \pm 44$ & $283 \pm 27$ & $0.238 \pm 0.123$ & $0.280 \pm 0.112$ \\
\hline Plant 2 & $7.87 \pm 0.21$ & $458 \pm 21$ & $284 \pm 13$ & $0.167 \pm 0.199$ & $0.155 \pm 0.139$ \\
\hline Plant 3 & $7.95 \pm 0.18$ & $481 \pm 55$ & $298 \pm 34$ & $0.566 \pm 0.111$ & $0.088 \pm 0.123$ \\
\hline WHO standards & $7.0-8.5$ & 700 & 500 & 0.3 & 0.05 \\
\hline
\end{tabular}

The results of Figure (1) showed that chlorination is employed primarily for microbial disinfection and acts as an oxidant to remove or assist in the removal of some chemicals by oxidation of dissolved species (e.g., manganese(II)) to form insoluble products that can be removed by subsequent filtration (WHO, 2006). A disadvantage of chlorine is its ability to react with natural organic matter to produce THMs and other halogenated DBPs. However, by-product formation may be controlled by optimization of the treatment system. In addition, manganese control in drinking water is receiving an increased attention due to its potential neurotoxicity (Sly et al., 1990). Manganese intake from water ingestion has been associated with intellectual impairment in children, even at low concentrations $(0.25 \mathrm{mg} / \mathrm{L})$ (Bouchard et al., 2011). Thus, it is crucial to effectively control the concentration of manganese in drinking water.

\section{pH}

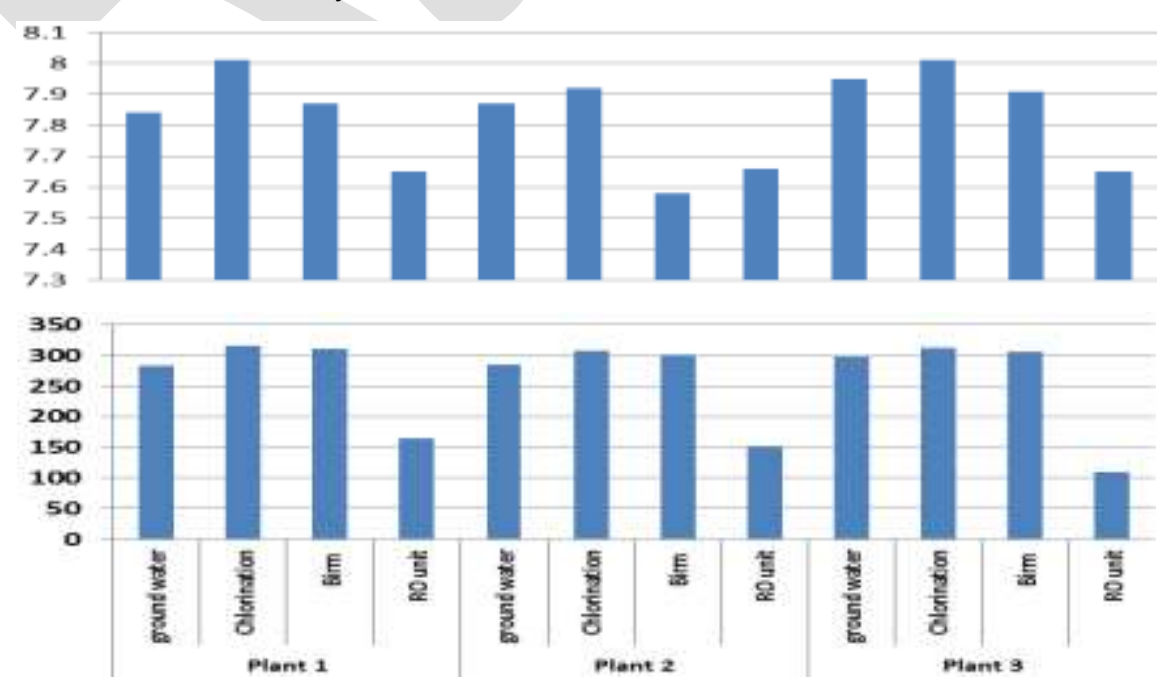

Figure (1): distribution of $\mathrm{pH}$ and total dissolved solids as TDS (ppm) through different treatement steps of compact units. 
The results of Figure (2) showed thatadverse effects of heavy metals are known since long ago, but the exposure to them continues and it is even increasing in some parts of the world, particularly in developing countries. Some metals are essential for life and are naturally available in our food and water. Toxic metals represent the ultimate form of persistent environmental pollutants because they are chemically and biologically indestructible. Health concerns associated with heavy metals in drinking water may arise from massive accidental contamination of a drinking water supply, but exposure comes primarily from prolonged periods of chronic exposure to trace doses of the metals; therefore, understanding the relationship between drinking-water quality and disease is very important (Arena et al., 2015). Some metals are essential and some are hazardous for

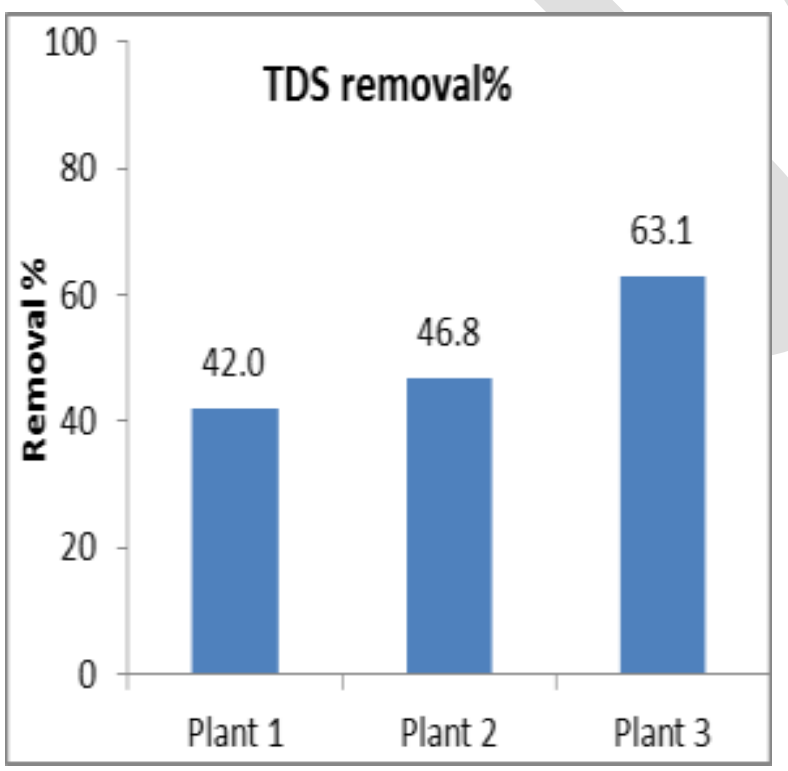

Figure (2): Removal\% of total dissolved solids through different treament compact units. body functioning (Copat et al., 2013; Copat et al., 2014).

The results of Figure (3) the groundwater is ultimate and most suitable fresh water resource with nearly balanced concentration of the salts for human consumption. Unfortunately, water resources are getting polluted and getting unfit for direct usage. Pollution of ground water aquifers has made many of the wells unfit for consumption. The availability of pure water through surface and groundwater resources has become more critical day today. Only $1 \%$ is available on earth for drinking purpose, agricultural purpose, domestic purpose, power generation, industrial consumption, transportation and waste disposal. There are several states in India where more than $90 \%$ of the total populations are dependent on groundwater for drinking and other purposes.

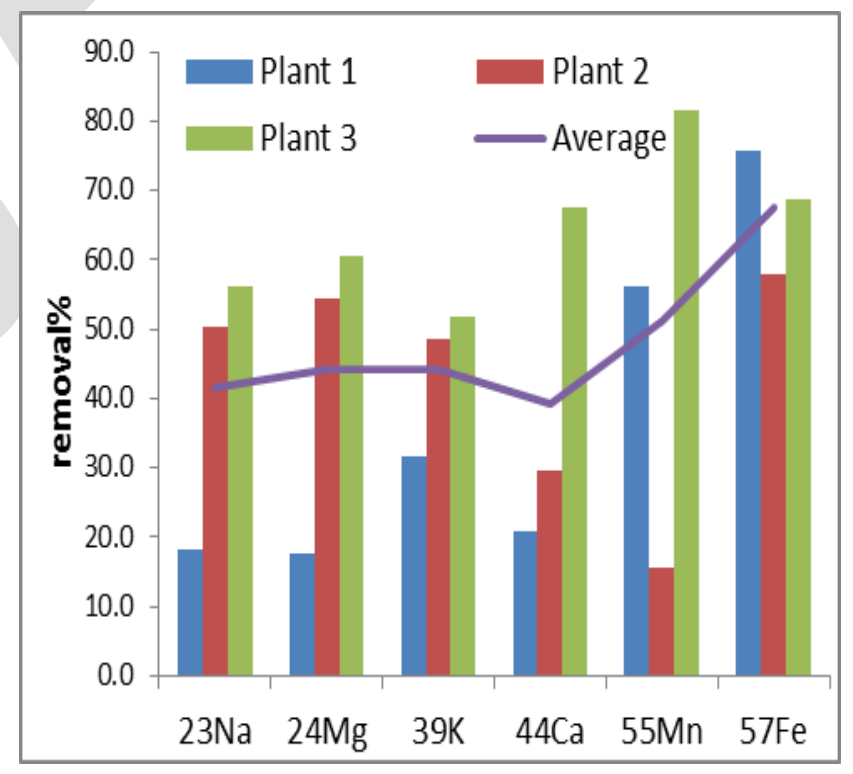

Figure (3): Removal\% of different metals ( $\mathrm{Na}, \mathrm{Mg}, \mathrm{K}$, and $\mathrm{Fe}$ ) and overall treatment efficiency averages through different water treament compact units. 
er

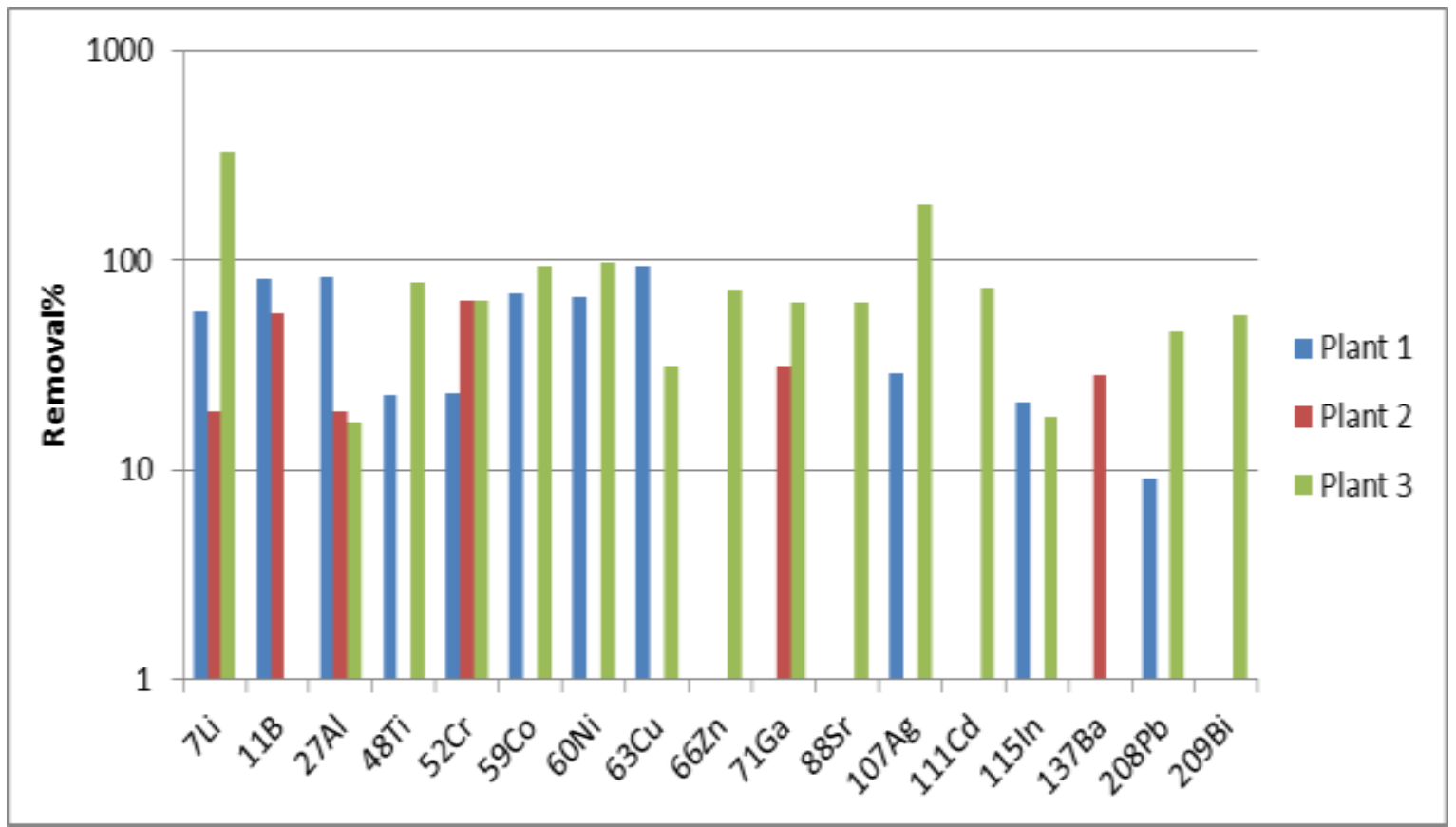

Figure (4) Removal\% offine concentrated metals through different water treament compact units.

The results of Figure (4) health effects from $\mathrm{Mn}$ ingestion are not a concern until concentrations are approximately 10 times $0.05 \mathrm{mg} / \mathrm{L}$. Ingestion of elevated Mnconcentrations from drinking water may cause neurological disorders (Alvarez-Bastida et al., 2013). An additional health concern that has not been addressed by regulators is the potential impact of adsorbed toxic metal ions released at elevated concentrations when $\mathrm{Mn}$ deposits disassociate.

\section{Wastewater characterization}

Table (2) showed measuring of certain physico-chemical variables has been the traditional approach to water quality assessment. Although specific chemical variables are useful to monitor and assess water quality, they only provide a short term picture of water quality at a source and each can only represent a portion of a complete assessment. This is actually the case in this study as physico-chemical characteristics of both raw and potable waters were used in conjunction of other biological parameters for an integrated assessment of water quality. 
Table (2) elements contents (ppm) of reject and wastewater and comparing with ground source.

\begin{tabular}{|c|c|c|c|}
\hline Elements (ppm) & Ground water & Reject water & Wastewater \\
\hline $\mathrm{Li}$ & 0.306 & 0.325 & 0.333 \\
\hline $\mathrm{B}$ & 0.706 & 0.751 & 0.806 \\
\hline $\mathrm{Na}$ & 42.206 & 44.9 & 55.0 \\
\hline $\mathrm{Mg}$ & 53.738 & 46.53 & 52.33 \\
\hline $\mathrm{Al}$ & 0.851 & 0.905 & 0.999 \\
\hline $\mathrm{K}$ & 48.617 & 51.72 & 58.64 \\
\hline $\mathrm{Ca}$ & 110.27 & 117.31 & 127.21 \\
\hline $\mathrm{Ti}$ & 0.893 & 0.950 & 3.877 \\
\hline $\mathrm{Cr}$ & 0.154 & 0.164 & 0.167 \\
\hline $\mathrm{Mn}$ & 0.105 & 1.92 & 2.103 \\
\hline $\mathrm{Fe}$ & 0.652 & 1.46 & 14.07 \\
\hline $\mathrm{Co}$ & 0.063 & 0.067 & 0.067 \\
\hline $\mathrm{Ni}$ & 0.005 & 0.012 & 0.011 \\
\hline $\mathrm{Cu}$ & 1.977 & 2.103 & 2.122 \\
\hline $\mathrm{Zn}$ & 0.865 & 0.92 & 1.22 \\
\hline $\mathrm{Ga}$ & 0.078 & 0.083 & 0.105 \\
\hline $\mathrm{Sr}$ & 1.026 & 1.091 & 1.093 \\
\hline $\mathrm{Ag}$ & 0.018 & 0.019 & 0.021 \\
\hline $\mathrm{Cd}$ & 0.046 & 0.049 & 0.056 \\
\hline $\mathrm{In}$ & 0.005 & 0.005 & 0.005 \\
\hline $\mathrm{Ba}$ & 0.007 & 0.0076 & 0.0074 \\
\hline $\mathrm{Pb}$ & 0.033 & 0.0356 & 0.0433 \\
\hline $\mathrm{Bi}$ & 0.005 & 0.0054 & 0.0058 \\
\hline & & & \\
\hline
\end{tabular}

However, from health and aesthetic point of views, some chemicals deserve special water quality significance, and, therefore, the World Health Organization (WHO, 2008) define the guidelines of water chemistry to insure safety for the health of consumers. The parameter selected for operational monitoring of drinking water quality should reflect the effectiveness of each control measure, provide a timely indication of performance, and be readily measured, and provide an opportunity for an appropriate response. Examples include measurable variables, such as chlorine residuals.

\section{REFERENCES}

Alemayehu, T (2004). Assessment of pollution status and ground water vulnerability mapping of the Addis Ababa water supply aquifers, Ethiopia. Leaflet distribution during the work shop 1628.

Alvarez-Bastida C, Martínez-Miranda V., Vázquez-Mejía $G$, Solache-Ríos $M$, Fonseca-Montes de Oca G, TrujilloFlores E. (2013). The corrosive nature of manganese in drinkingwater. Sci. Total Environ 447:10-6.
American Public Health Association [APHA] (2005) Standard Methods for the Examination of Water and Wastewater $22^{\text {nd }}$ ed. APHA, Inc. Washington, D.C.

Bouchard MF, Sauve S, Barbeau B, Legrand M, Brodeur ME, Bouffard T, (2011) Intellectual impairment in school-age children exposed to manganese from drinking water. Environ Health Perspect 119:138-43.

Copat, C., Arena, G., Fiore, M., Ledda, C., Fallico, R., Sciacca, S., Ferrante, M., 
(2013). Heavy metals concentrations in fish and shellfish from eastern Mediterranean Sea: consumption advisories. Food Chem. Toxicol. 53, 33-37.

Copat, C., Vinceti, M., D'Agati, M.G., Arena, G., Mauceri, V., Grasso, A., Fallico, R., Sciacca, S., Ferrante, M., (2014). Mercury and selenium intake by seafood from the Ionian Sea: a risk evaluation. Ecotoxicol. Environ. Saf. 100, 87-92.

Crittenden, J.C.,Trussell, R.R., Hand, D.W., Howe, K.J.,Tchobanoglous, G. (2012) MWH's Water Treatment: Principles and Design, $3^{\text {rd }}$ ed., John Wiley \& Sons, Inc., Hoboken, NJ.

EPA, (2002) US Environment Protection Agency, Safe Drinking Water Act Amendment

http://www. EPA.gov/safe water/mcl.Html

Lambers, H., Chapin, F. S., Pons, T. L. (2008) Plant Physiological Ecology. Second Edition, (Springer Science, LLC, 233, New York, USA).

Lee, S.J., Kim, J.H. (2014) Differential natural organic matter fouling of ceramic versus polymeric ultrafiltration membranes. Water Res.48, 43-51.

Mishra, K.R.,Pradip, S.P.,Tripathi, G. (2002) Groundwater quality of open wells and tube wells, ActaCiencialndica, 2, 179186.

Rajic L., Nazari R., Fallahpour N., Alshawabkeh A.N.(2016).
Electrochemical degradation of trichloroethylene in aqueous solution by bipolar graphite electrodes. J. Environ. Chem. Eng. 4: 197-202.

Sly, L.I.,Hodgkinson, M.C.,Arunpairojana, V. (1990) Deposition of manganese in a drinking water distribution system. Appl.Environ.Microbiol.56, 628-639.

Stavridis, Ch.,Patsakidou, Th.,Katsifarakis, K.L. (2017) Use of Groundwater Resources in Urban Areas. Environmental Benefits and Cost Considerations.

Procedia

Environmental Sciences 38: 860 866.

USEPA (U.S. Environmental Protection Agency) (2015) Regulated drinking water contaminants. Online database Available at: http://www.epa.gov/dwstandardsregula tions\#Disinfectants (Accessed on Dec 02, 2017).

WHO (World Health Organization) (2004) Guidelines for Drinking-water Quality. Geneva, vol. 2. World Health Organization, Geneva.

WHO (World Health Organization)(2011). Guidelines for Drinking-water Quality. Fourth ed. World Health Organization, Geneva.

WHO (World Health Organization) (2006) Guidelines for drinking-water quality [electronic resource:incorporating first addendum. Vol. 1, Recommendations. $3^{\text {rd }}$ ed. World Health Organization, Geneva. 